\title{
Dust emission reduction for open storage mineral piles by fences: CFD modelling
}

\author{
S. Torno, R. Rodriguez, C. Allende \& J. Toraño \\ School of Mines, University of Oviedo, Spain
}

\begin{abstract}
The significance of the dust emission study in open mineral storage piles is due to the great increase in bulk solids port terminals as a result of the increase in demand for different granular mineral.

These piles are a significant source of pollutants into the atmosphere since they are affected by gusts of wind. The wind erodes the pile surface causing windblown particles to pollute the surrounding areas, cause sea water pollution in Port Systems and/or breathable air pollution in nearby areas.

There are various preventive measures which minimize the erosion produced by the wind, such as total or partial covering, the use of water and chemical spraying which create a superficial crust and the colocation of natural or artificial fences (more widely used).

In this research, the effect of different types of fence configurations, such as, straight, curved and with a bottom gap, for the particle emissions into the atmosphere has been analyzed by means of the Post Method which has been carried out by our Research Group incorporating Ansys CFX-10.0 software the US EPA (United States Environmental Protection Agency) emission formulae. The results obtained in this method have been proved and adjusted by measurement programmes that have been carried out in industrial installations.

The best results correspond to the straight fence with a bottom gap located as much upstream as downstream from the pile.
\end{abstract}

Keywords: particle emission, computational fluid dynamics (CFD), open storage pile, air pollution, dust barrier. 


\section{Introduction}

The significance of the dust emission study in open mineral storage piles is due to the great increase in bulk solids port terminals as a result of the increase in demand for different granular mineral.

These mineral accumulations are affected by the wind, causing surface erosion, windblown particles and health and environmental risks. In fact, this is widely studied by the authors in a research carried out within an $\mathrm{I}+\mathrm{D}+\mathrm{I}$ Project supported by funds from the Spanish National Research and Development Plan of the Ministry of Education and Science.

In the first phase of this research, the wind effect over the piles has been studied $[1,2]$, determining different subzones where the erosion was produced taking into account threshold friction velocity and the erosion ratio for different pile geometries.

In the last research phase, artificial barriers were placed adjacent to the pile in order to diminish the dust emission produced by wind action over the open storage piles, determining that dust emission to the atmosphere was reduced for the worst environmental and operational conditions by $66 \%$ (Toraño et al [3]).

Nevertheless, by using solid barriers a high velocity vortex between the barrier and the pile was produced, causing a greater dust emission to windward of pile [4-6]. Different types of barriers have been taken into account in order to avoid this emission.

Firstly, the effect of the porous barriers at 30\% adjacent to the pile has been studied, achieving an emission reduction produced to windward of pile due to the solid barrier effect over the wind flow (Torno et al [7]).

In this paper, the research on how different barrier configurations (straight, curved and those with bottom gaps) affect the high velocity wind vortex produced by solid barriers is continued $[8,9]$. In this case, we have used the Post Method, which allows one to determine the particle emission from the pile surface by means of CFD modelling in Ansys CFX-10.0 software [3]. By means of this calculation methodology and by utilizing the most efficient barrier, according to results presented in [3], it is determined that straight barriers with bottom gaps of 2 meters are those which most minimize the particle emission to the atmosphere.

\section{Methodology}

\subsection{CFD modelling}

The Computational Fluid Dynamics (CFD) is fundamentally base on the resolution of a set of equations which describe the processes of momentum, heat and mass transfer in a moving fluid and are known as the Navier-Stokes equations, widely explained in [1-3]. These partial differential equations have no known general analytical solution but can be discretised and solved numerically.

The Numerical Method used to resolve these equations is the Fite Volume Method containing a Eulerian behaviour. 
These expressions form a partial differential equation system, this is coupled for linear form, and therefore CFD is used to the solution. And within CFD, the software Ansys CFX 10.0 (working by mineral codes) is chosen by the authors to resolve the problem.

Since tests have been carried out by different turbulence models, k-epsilon model has been chosen for our research.

The CFD modelling, by software Ansys CFX-10.0 [10], start with a geometry created by SolidWorks. This geometry consists of a $11 \mathrm{~m}$ high conical pile and a $1.2 \mathrm{H}$ high barrier. The barrier being/is placed at a distance of $3 \mathrm{H}$ from the pile, where $\mathrm{H}$ is the pile height (since it is the barrier which minimises the dust emission to the atmosphere).

The geometry meshing carried out by software IcemCFD 10.0 approximately contains 2 million elements with finer meshing areas over the pile and the barrier, characterised by a quality of 0.38 . The model domain is a (100 high $\mathrm{x}$ 110 wide x 350 long) box, with 3 boundary conditions, Inlet, Outlet and Wall. The air enters the model by the Inlet, according to the logarithmic wind profile with a velocity of $11.11 \mathrm{~m} / \mathrm{s}$ at $10 \mathrm{~m}$ high, USEPA [11]. The air freely emerges from the model by the Outlet. The remaining surfaces are considered as Wall.

In figure 1, the geometry and barrier meshing are shown. The left figures correspond to CFD modelling for the $1 \mathrm{~m}$ bottom gap straight barrier, whereas the right figures correspond to CFD modelling for the $2 \mathrm{~m}$ bottom gap curved barrier. For both barrier configurations, the domain and the meshing plane transversal to model are shown, where the finer meshing over barrier and pile can be seen.
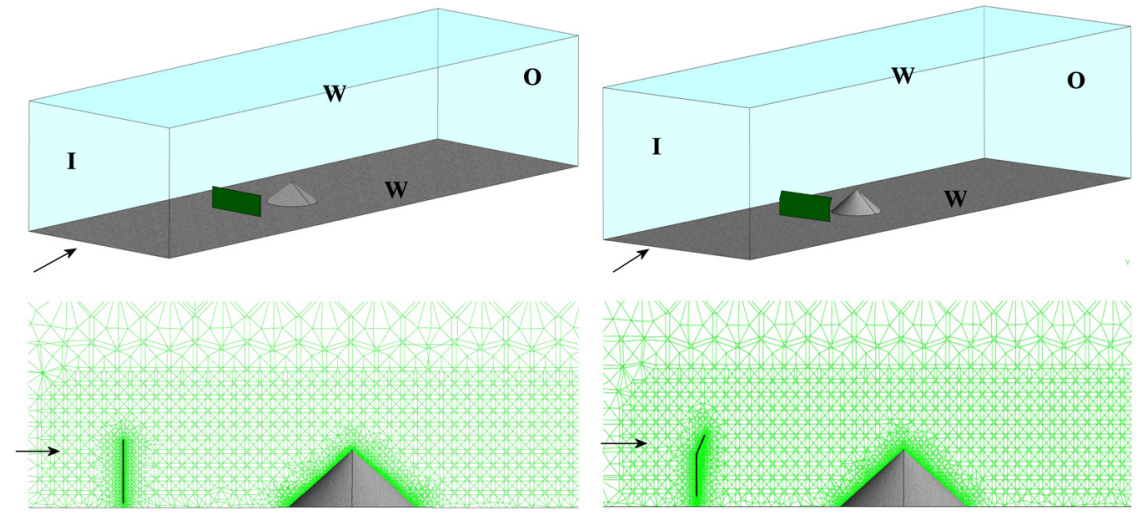

Figure 1: Geometry and barrier meshing, $(\mathrm{I}=$ Inlet, $\mathrm{O}=$ Outlet, $\mathrm{W}=$ Wall and $\operatorname{Arroz}=$ wind direction).

\subsection{Post method}

The total dust emission for open aggregate storage pile, (in unfavourable conditions) has been calculated by the Post Method methodology. This method is found to be widely validated with experimental data (30 tests) and the obtained 
result in [3], where wind velocity profile and dust emissions have been measured in order to validate CFD modelling.

In order to carry out a Post Method study, it is necessary to create a revolution surface placed a fixed distance from the pile surface, (fixed by EPA at $25 \mathrm{~cm}$ from a pile at $11 \mathrm{~m}$ height). The latter surface is divided into "face", where emissions are calculated.

According to the wind velocity distribution over the pile surface, it is possible to qualitatively by and quantitatively estimate in which area of the pile the dust emission is produced. This emission area is determined by EPA formulation, which indicated that the emission is produced when the friction velocity $\left(u^{*}\right)$ is greater than threshold friction velocity $\left(u_{t}{ }_{t}\right)$, eqn. (1).

$$
\begin{aligned}
& P=58\left(u^{*}-u_{t}^{*}\right)^{2}+25\left(u^{*}-u_{t}^{*}\right) \\
& P=0 \text { for } u^{*} \leq u_{t}^{*}
\end{aligned}
$$

This Emission is implemented is the software by mean of eqn (2):

$$
\text { Emission }=\mathrm{K} \times(\mathrm{P} \times \text { Conditional })
$$

Where, Conditional is the emission characteristic [11] and $\mathrm{K}$ is the particle size multiplier.

\section{Presentation and discussion of the results}

The obtained results for the barrier height $1.2 \mathrm{H}(13.2 \mathrm{~m})$ placed at $3 \mathrm{H}(33 \mathrm{~m})$ have been used for the CFD modelling as this indicates the minimum dust emission to the atmosphere [3].

Six modelling have been carried out for each studied barrier configurations:

- 1 modelling with solid vertical straight barrier without bottom gap.

- 2 modelling with both solid straight barrier and bottom gaps of 1 and $2 \mathrm{~m}$.

- 1 modelling with curved solid barrier without bottom gap.

- 2 modelling with both curved barriers and bottom gaps of 1 and $2 \mathrm{~m}$.

In table 1, the dust emission results obtained for the six modelling are shown in kilograms. It can be seen that straight barrier emission values are lower than curved barrier values (due to the velocity distribution over the pile), where the

Table 1: $\quad$ Dust emission $(\mathrm{kg})$.

\begin{tabular}{|c|c|c|}
\hline \multicolumn{3}{|c|}{ Emission (kg) } \\
\hline & Straight barrier & Curved barrier \\
\hline Solid barrier & 246 & 275 \\
\hline With bottom gap of $1 \mathrm{~m}$ & 222 & 262 \\
\hline With bottom gap of $2 \mathrm{~m}$ & 152 & 216 \\
\hline
\end{tabular}


lower emission value corresponds to the straight barrier with a bottom gap of $2 \mathrm{~m}$.

For the initial modelling (both straight and curved barriers without bottom gaps), fundamentally difference is that the lower velocity zones to windward of pile are of smaller size in the case of curved barriers. Additionally, for these curved barriers the wind flow vortex behind the barrier produce a area of greater size with higher velocities than straight barriers.

In figure 2, a velocity boundary for the modelling without bottom gap is shown. A high velocity wind vortex which produces dust emission to windward of the pile is created between the barriers and the pile. In order to diminish these vortex effects bottom gaps of 1 and $2 \mathrm{~m}$ are incorporated to the latter barriers.

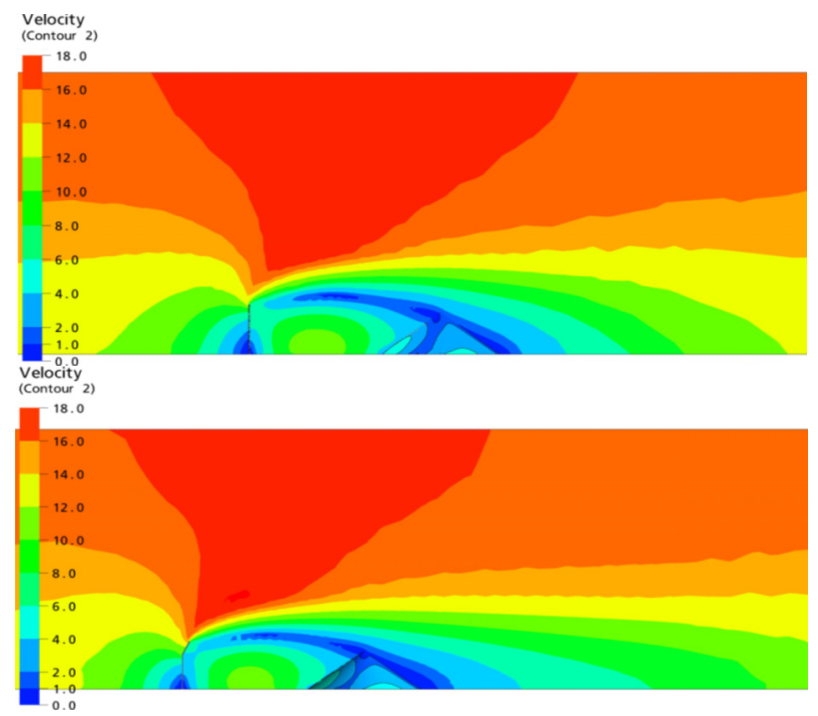

Figure 2: Velocity distribution for straight and curved barriers without bottom gaps.

In figure 3 velocities distribution for the straight and curved barriers with bottom gaps of $1 \mathrm{~m}$ are shown. By introducing this bottom gap, the vortex rapidly diminishes its velocity ranging from $(10-8) \mathrm{m} / \mathrm{s}$ to $(6-8) \mathrm{m} / \mathrm{s}$ over the vortex centre. This provokes low velocity areas to become greater.

Lastly, for barrier modelling with bottom gaps of $2 \mathrm{~m}$ shown in figure 4 it can be seen how the vortex diminishes its velocity (4-6) $\mathrm{m} / \mathrm{s}$ creating low velocity areas of greater size over the pile surface.

In figure 5, the wind velocity distribution over the pile surface for the two modelling with minimum and maximum emission is shown, where the minimum emission corresponds to the straight barrier with bottom gap of 2 metres and the maximum corresponds to the curved barrier without bottom gap. 


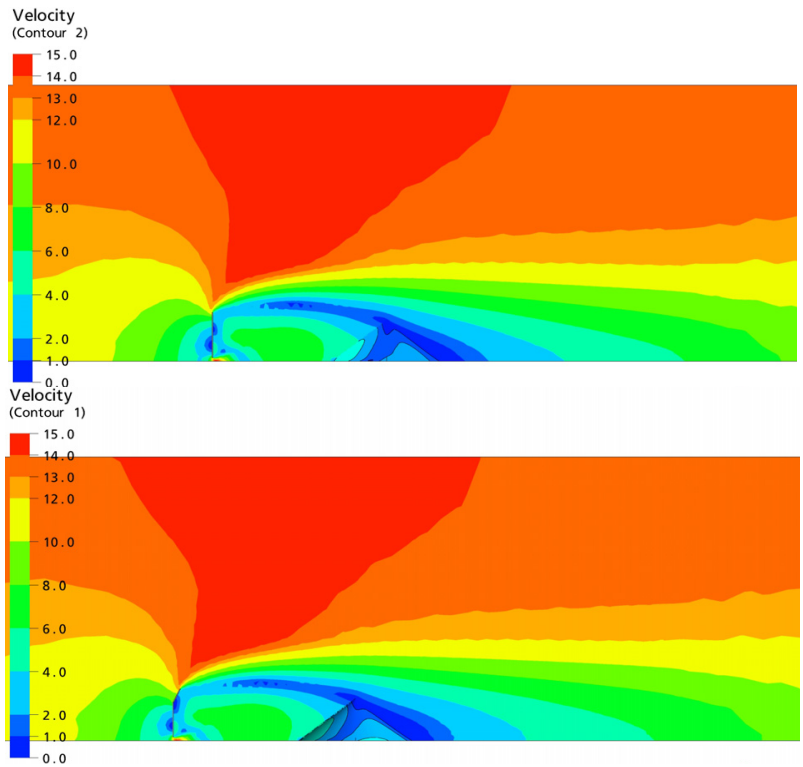

Figure 3: Velocity distribution for straight and curved barriers with bottom gaps of $1 \mathrm{~m}$.

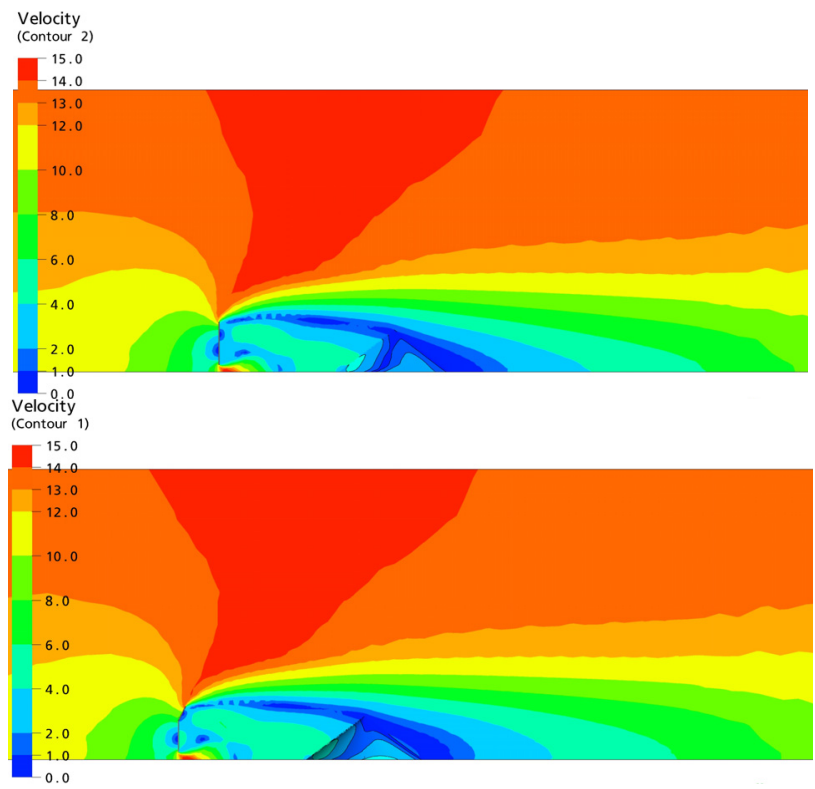

Figure 4: Velocity distribution for straight and curved barriers with bottom gaps of $2 \mathrm{~m}$. 

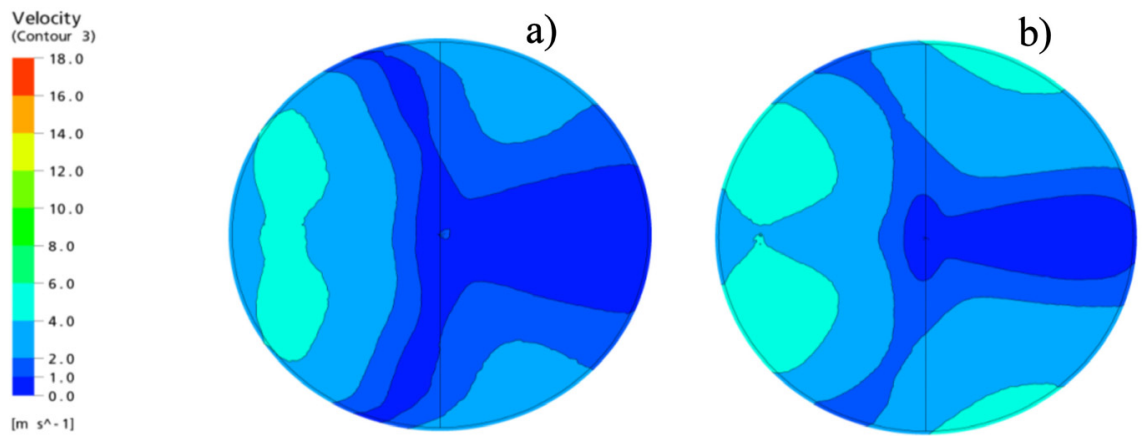

Figure 5: Wind velocity distribution over the pile surface for the emission a) minimum and b) maximum.

\section{Conclusions}

Dust emission into the atmosphere, produced by wind action over open aggregate storage piles can be widely studied by means of Computational Fluid Dynamics and Post Method.

Dust emission can be considerably reduced to $60 \%$ for the worst environmental and operational conditions by incorporating barriers adjacent to the pile.

A higher velocity wind vortex, which affects the pile, is created by the barriers. In this paper different barrier configurations have been studied so as to diminish these vortex velocities and also to achieve more effectiveness to face the emission.

Both straight and curved barriers with bottom gaps of 1 and $2 \mathrm{~m}$ have been considered, achieving better results from straight barriers with bottom gap of 2 $\mathrm{m}$. Consequently, the minimum emission value corresponds to straight barriers with bottom gap of $2 \mathrm{~m}$.

\section{References}

[1] Toraño, J., Rodríguez, R., Diego, I., Rivas, J.M. \& Pelegry, A., Influence of the pile shape on wind erosion CFD emission simulation. Applied Mathematical Modelling, 31, pp. 2487-2502, 2007.

[2] Diego, I., Pelegry, A., Torno, S., Toraño, J. \& Menendez, M., Simultaneous CFD evaluation of wind flow and dust emission in open storage piles. Applied Mathematical Modelling, 33, pp. 3197-3207, 2009.

[3] Toraño, J., Torno, S., Menéndez, M. \& Gent, M., Dust emission calculations in open storage piles protected by means of barriers, CFD and experimental tests. Environmental Fluid Mechanics, 9, pp. 493-507, 2009.

[4] Diego, I., Rodríguez, R. \& Toraño, J., Surface velocity contour analysis in the airborne dust generation due to open storage piles. ECCOMAS 2006, pp. 1-12, 2006. 
[5] Lee, S.J. \& Lim, H.CH., A numerical study on around a triangular prism located behind a porous fence. Fluid Dynamics Research, 28, pp. 209-221, 2001.

[6] Kim, H.B. \& Lee, S.J., Hole diameter effect on flow characteristics of wake behind porous fences having the same porosity. Fluid Dynamics Research, 28, pp. 449-464, 2001.

[7] Torno, S., Toraño, J., Diego, I., Menéndez, M., Gent, M. \& Velasco, J., CFD simulation with multiphase flows in porous media and open mineral storage pile. WIT Transactions on Engineering Sciences, 63, pp. 421-430, 2009.

[8] Torno, S., Emisiones de Material particulado en el almacenamiento de minerales a la intemperie. Ph.D. Oviedo University, Ed. Ediuno, pp. 1-382, 2008.

[9] Kim, H.B. \& Lee, S.J., The structure of turbulent shear flow around a twodimensional porous fence having a bottom gap. Journal of Fluids and Structures, 16(3), pp. 317-329, 2002.

[10] Ansys CFX ANSYS CFX- Solver. Release 10.0 ANSYS CFX-Solver, Release 10.0: Modelling pp 327.

[11] US EPA Sections 13.2.4 and 13.2.5 Compilation of air Pollutant Emission Factors. 